\title{
Effects of sivelestat sodium hydrate on the reduction of radiation pneumonitis
}

\author{
TAIJU SHIMBO $^{1}$, TAISUKE INOMATA ${ }^{1}$, MASATSUGU TAKAHASHI $^{1}$, TOSHIAKI TATSUMI $^{1}$, \\ YASUO UESUGI ${ }^{1}$, ISAMU NARABAYASHI ${ }^{1}$ and HIROSHI SONOBE ${ }^{2}$ \\ ${ }^{1}$ Department of Radiology, Osaka Medical College, Osaka 569-0855; \\ ${ }^{2}$ Department of Clinical Inspection, Chugoku Central Hospital, Hiroshima 720-0001, Japan
}

Received August 13,2007; Accepted September 26, 2007

\begin{abstract}
In this study, we irradiated the murine lung and analyzed the inhibitory effects of sivelestat sodium hydrate, a neutrophil elastase (NE) inhibitor, on lung injury in mice. Sivelestat sodium hydrate $(3 \mathrm{mg} / \mathrm{kg})$ was administered by intraperitoneal injection immediately, 3, 6, and $12 \mathrm{~h}$ after irradiation in groups RE-0, RE-3, RE-6, and RE-12, respectively. A control group and a group receiving radiation without sivelestat (group R) were also used. NE activity was measured 24 and $48 \mathrm{~h}$ after irradiation. The lungs were simultaneously extirpated and stained with hematoxylin and eosin and a naphthol AS-D chloroacetate esterase stain $(\mathrm{N}$ ASDCLA). NE activity increased in the groups in which the murine lungs were irradiated. There was no increase in NE activity in the control group. Among the sivelestatadministered groups, NE activity was slightly elevated in group RE-0 and was suppressed, compared to group R, in groups RE-3, RE-6, and RE-12 at $24 \mathrm{~h}$ after irradiation. In the irradiated groups, intra-alveolar neutrophil infiltration, perivascular edema, and alveolar wall thickness were observed, but these changes were mild in the sivelestat-administered groups. The number of N-ASDCLA-positive cells increased in the sivelestat-administered groups, while group $\mathrm{R}$ had low values. This indicated that sivelestat sodium hydrate blocked the release of NE from the neutrophils in the irradiated lungs. NE plays an important role in the development of radiationinduced lung injury. Sivelestat is thus expected to decrease radiation-induced lung toxicity by suppressing NE release from neutrophils.
\end{abstract}

\section{Introduction}

Clinically observed radiation pneumonitis usually develops 4-6 weeks after the completion of radiation therapy, rarely

Correspondence to: Dr Taiju Shimbo, Department of Radiology, Osaka Medical College, 2-7 Daigaku-machi, Takatsuki-shi, Osaka 569-0855, Japan

E-mail: rad089@poh.osaka-med.ac.jp

Key words: neutrophil elastase, radiation pneumonitis, sivelestat sodium hydrate becoming a serious condition. However, some types of acute radiation pneumonitis can become serious, sometimes resulting in mortality. Consequently, we should be alert to the possibility of this condition when conducting radiation treatment (1). Despite reports showing the efficacy of steroid therapy for acute radiation pneumonitis, so far no treatment has been established scientifically (2-5).

Sivelestat sodium hydrate, ONO-5046 • Na (Elaspol ${ }^{\circledR}$, Ono Pharmaceutical) is a synthetic elastase inhibitor developed in Japan. It has an extremely small molecular weight of 528.5 Da and is known to specifically and antagonistically inhibit human neutrophil elastase. Moreover, experiments have shown its efficacy in animal models of lung injuries caused by endotoxin (6), cobra toxin (7) (which is a complement activator), bleomycin $(8)$, and hydrochloric acid $(9,10)$. Today it is widely used in clinics to improve acute lung injury accompanying systemic inflammatory response syndrome caused by aspiration pneumonia, surgery, injury, and infection (11-14). Experimental studies have shown that, in the case of radiation-induced lung injury, the immediate release of proinflammatory cytokines such as TNF- $\alpha$, IL- 1 and IL-6 after lung irradiation is closely related with lung toxicity. The increase in these cytokines activates neutrophils, resulting in an accumulation of the activated neutrophils in the lung and the release of elastase. Neutrophil elastase (NE), which is present in the azurophil granules of neutrophils, is deeply involved in the non-specific phylaxis of neutrophils. When neutrophils are activated by stimulation, NE is released from the granules extracellularly, thereby accelerating the permeability of the vascular endothelial and alveolar cells of the lung (15-17). Due to its low substrate specificity, NE disintegrates extracellular matrices, such as collagen, proteoglycan, and fibronectin, and impairs tissue, thereby causing lung injury (18-20). There have been no previous reports on the inhibitory effects of NE on radiation-induced lung injury in animal models. In the present study, we irradiated the murine lung and analyzed the inhibitory effects of sivelestat, an NE inhibitor, on lung injury in mice.

\section{Materials and methods}

Animal model. Twelve-week-old female C57BL/6J mice were used. The animals were kept in an air-conditioned room at $23 \pm 2^{\circ} \mathrm{C}$ and $55 \pm 10 \%$ humidity for $24 \mathrm{~h}$ in a 12 -h light/dark 
Table I. Stratification of the mice.

\begin{tabular}{|c|c|c|c|c|c|c|}
\hline \multirow[b]{2}{*}{ After irradiation (h) } & \multicolumn{6}{|c|}{ Groups } \\
\hline & $\mathrm{C}$ (control) & $\mathrm{R}(12 \mathrm{~Gy})$ & RE-0 (12 Gy) & RE-3 (12 Gy) & RE-6 (12 Gy) & RE-12 (12 Gy) \\
\hline 0 & & & Elaspol & & & \\
\hline 3 & & \multicolumn{5}{|c|}{ Elaspol } \\
\hline 6 & & & & \multicolumn{3}{|c|}{ Elaspol } \\
\hline 12 & & & & & & Elaspol \\
\hline 24 & \multicolumn{6}{|c|}{$\begin{array}{l}\text { Measurement of NE activity in the blood plasma } \\
\text { Extirpation of the lungs }\end{array}$} \\
\hline 48 & \multicolumn{6}{|c|}{$\begin{array}{c}\text { Measurement of NE activity in the blood plasma } \\
\text { Extirpation of the lungs }\end{array}$} \\
\hline
\end{tabular}

cycle, and cared for with food and water. This experiment was conducted with the approval of the Experimental Animal Ethics Committee at Osaka Medical School Hospital.

Drugs and reagents. Sivelestat sodium hydrate (neutrophil elastase inhibitor, NO-5046 • Na (sodium-[2-[4-(2,2dimethethyl-propionyloxy) phenylsulfonylamino] benzoyl] aminoacetate tetrahydrate) was dissolved in normal saline solution with a small amount of added sodium carbonate.

Experimental design. In this study, six groups consisting of seven mice were used (Table. I). The mice were fixed on an exclusive jig. The radiation field is shown in Fig. 1. A dose of $12 \mathrm{~Gy}$, with a 4-MV photon beam was delivered to the whole lung in a single fraction via a posterior field with a linear accelerator under Nembutal anesthesia. Sivelestat (3 mg/ $\mathrm{kg}$ ) was administered through intraperitoneal injection immediately, 3, 6, and $12 \mathrm{~h}$ after irradiation in groups RE-0, RE-3, RE-6, and RE-12, respectively. A control group (group
C) and a group which received radiation without sivelestat (group R) were also used. NE activity was measured 24 and $48 \mathrm{~h}$ after irradiation.

Evaluation of the effects of sivelestat sodium hydrate. We obtained blood samples via cardio-puncture from the animals, under Nembutal anesthesia, 24 and $48 \mathrm{~h}$ after irradiation. After obtaining the supernatant by blood centrifuge $(1,700 \mathrm{x} \mathrm{g}$, $10 \mathrm{~min}, 4^{\circ} \mathrm{C}$ ) and immediately freezing it for preservation at $-20^{\circ} \mathrm{C}$, we measured the neutrophil elastase (NE) activity level in the blood plasma via absorption spectroscopy, using the specific synthetic substrate N-methoxysuccinyl-Ala-Pro-Val (pNA) for NE (6). Blood plasma was incubated in $0.1 \mathrm{M}$ Tris-HCL buffer solution ( $\mathrm{pH} 8.0$ ) containing $0.5 \mathrm{M} \mathrm{NaCl}$ and $1 \mathrm{mM}$ substrate for $24 \mathrm{~h}$ at $37^{\circ} \mathrm{C}$. The absorbance of free pNA at $405 \mathrm{~nm}$ was measured on a microplate reader. Next, mice were sacrificed, and the lungs were removed and fixed in formalin. The lungs were simultaneously extirpated and stained with hematoxylin and eosin and an N-ASDCLA. The

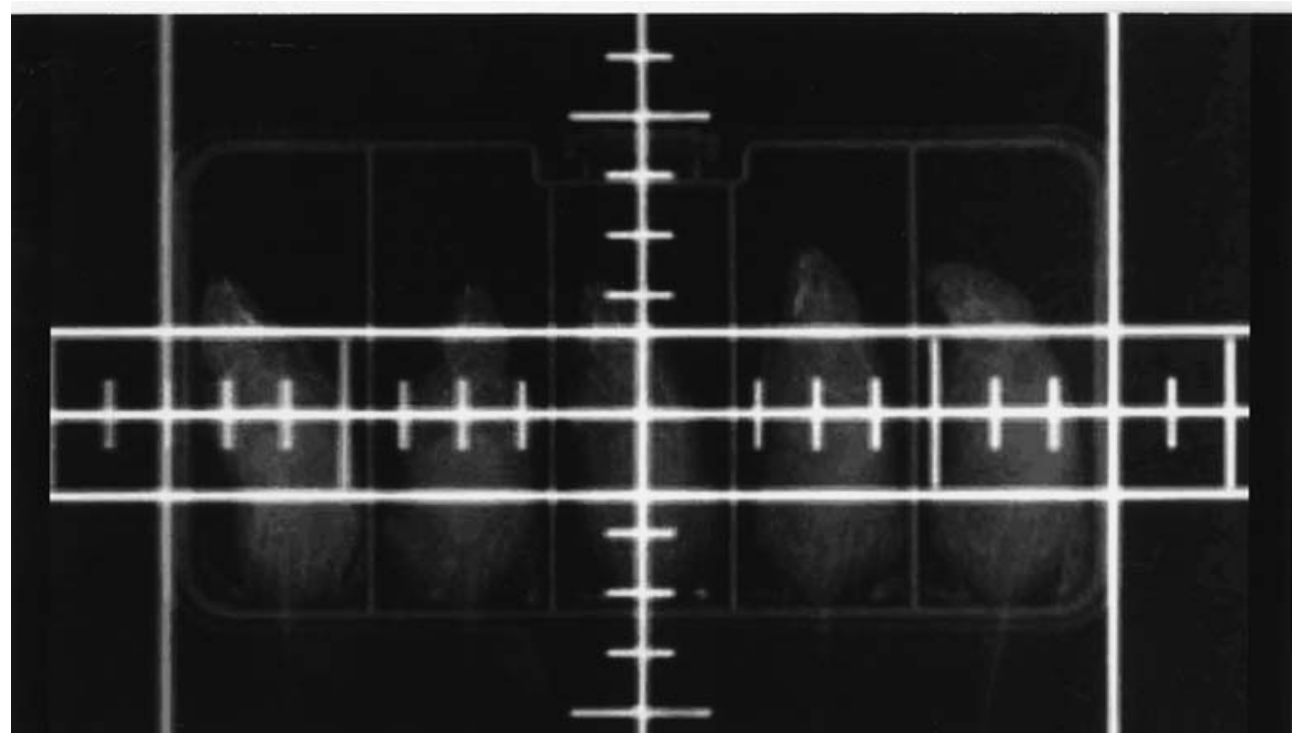

Figure 1. Irradiation field. The mice were fixed on an exclusive jig. A dose of 12 Gy, with a 4-MV photon beam was delivered to the whole lung in a single fraction via an anterior field with a linear accelerator under Nembutal anesthesia. 


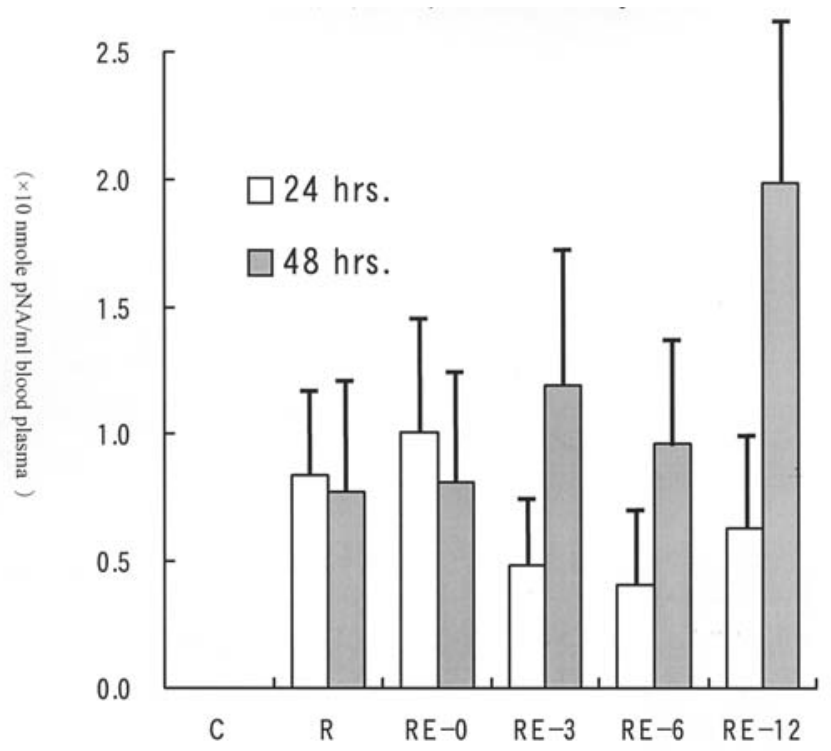

Figure 2. The neutrophil elastase activity level in the blood plasma. NE activity increased in the groups in which murine lungs were irradiated. There was no increase in NE activity in group C. At $24 \mathrm{~h}$ after irradiation, compared to the $\mathrm{R}$ group, NE activity was slightly increased in the RE-0 group and was suppressed in the RE-3 ( $\mathrm{p}=0.04)$, RE-6 ( $\mathrm{p}=0.02)$, and RE-12 $(p=0.29)$ groups. In the RE-3 and RE-6 groups NE activity was significantly suppressed compared to the $\mathrm{R}$ group. At $48 \mathrm{~h}$ after irradiation, compared to the $\mathrm{R}$ group, NE activity was increased in all the sivelestat-administered groups; RE-0 ( $p=0.86), R E-3(p=0.29), R E-6(p=0.41)$, and RE-12 $(p<0.01)$. In the RE-12 group NE activity was significantly increased compared to the $\mathrm{R}$ group. histopathological features of these cross sections were analyzed and N-ASDCLA-positive cells were counted under an optical microscope.

\section{Results}

NE activity (Fig. 2). NE activity increased in the groups in which the murine lungs were irradiated. There was no increase in NE activity in group C. Among the sivelestat-administered groups, NE activity was slightly elevated in the RE-0 group and was significantly suppressed in groups RE-3 $(\mathrm{p}=0.04)$ and RE-6 $(p=0.02)$, compared to group $R$ at $24 \mathrm{~h}$ after irradiation. Forty-eight hours after irradiation, the value of the RE-12 group was significantly increased compared to group $\mathrm{R}(\mathrm{p}<0.01)$.

\section{Histopathological features}

Hematoxylin and eosin stain (Fig. 3). In the irradiated groups, intra-alveolar neutrophil infiltration, perivascular edema, and alveolar wall damage were observed, but these changes were mild in the sivelestat-administered groups.

Naphthol AS-D chloroacetate esterase stain (Figs. 4 and 5). N-ASDCLA showed strong activation in neutrophillineage cells, while elastase-positive granules were stained red-brown (Fig. 4). The number of N-ASDCLA-positive cells increased in the sivelestat-administered groups, while group $\mathrm{R}$ had low values. Twenty-four hours after irradiation, the RE-0 group value was high while the values of the RE-3,

(C)

(R)
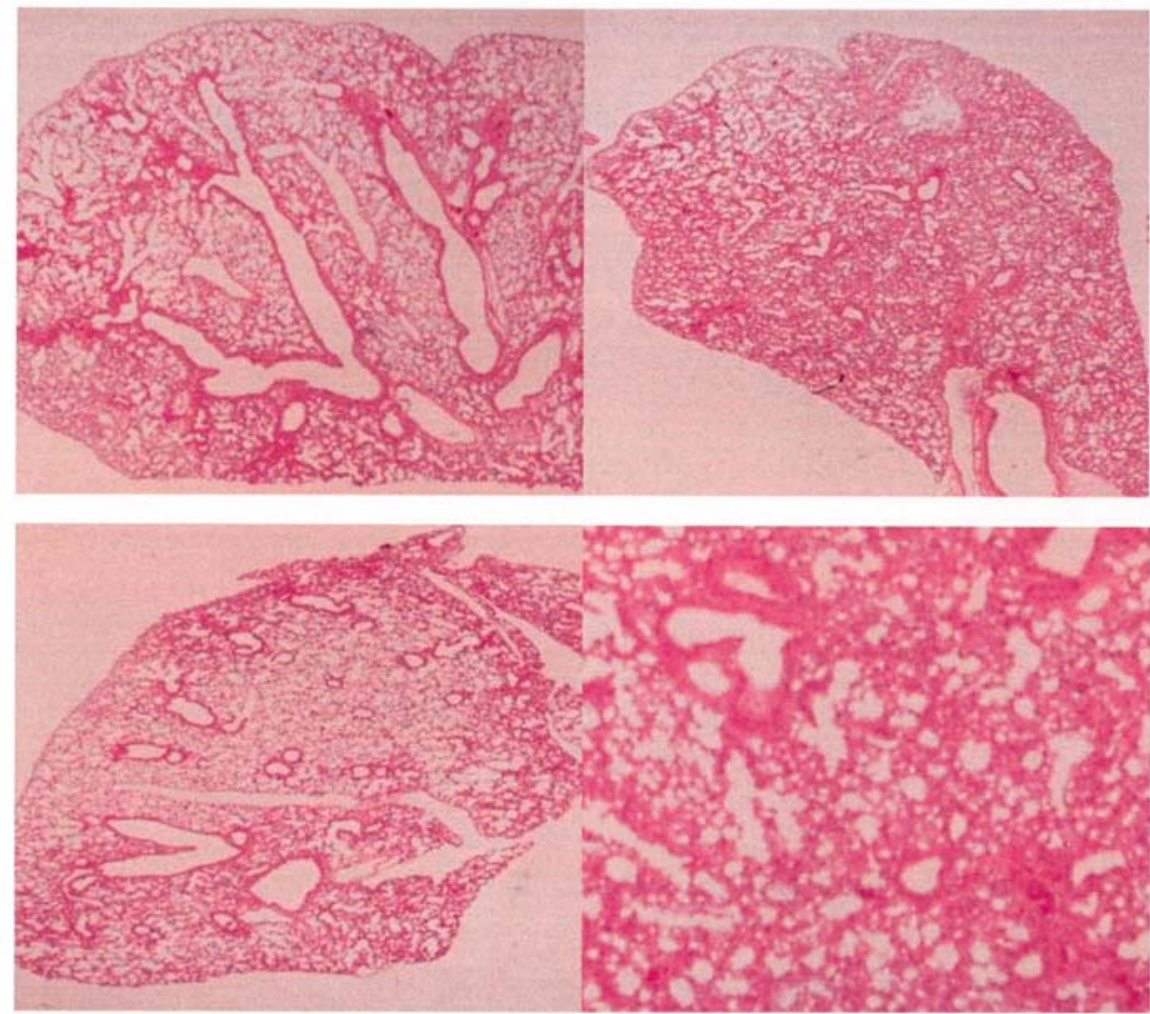

(RE-3)

(R: Strong magnification)

Figure 3. Hematoxylin and eosin stain. Compared to the control group, in the irradiated groups (R), intra-alveolar neutrophil infiltration, perivascular edema, and alveolar wall damage were observed, but these changes were mild in the sivelestat-administered groups (RE-3). 


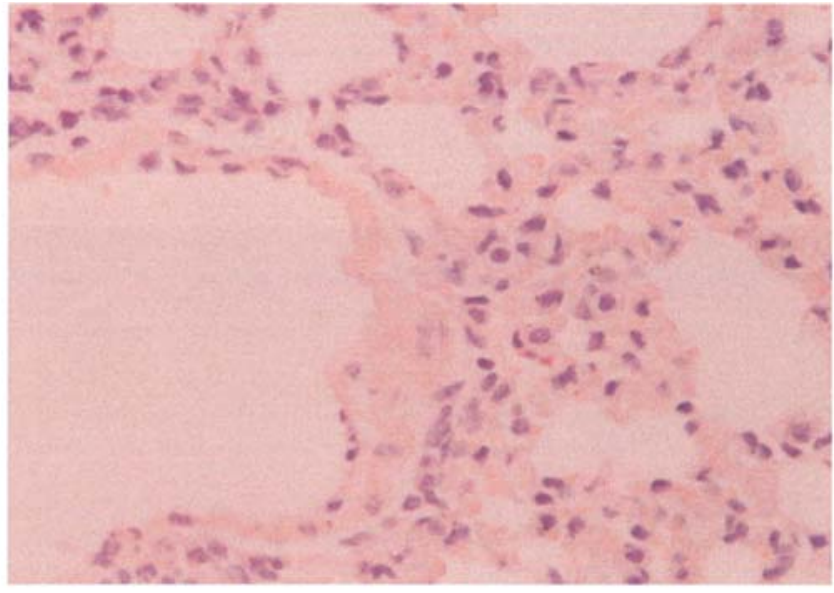

(C)

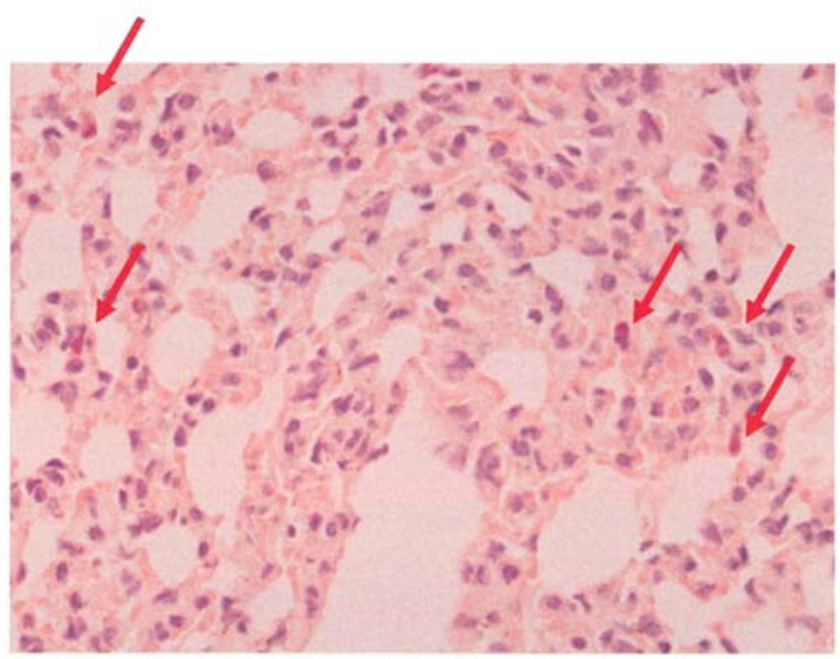

(RE-3)

Figure 4. Naphthol AS-D chloroacetate esterase stain. N-ASDCLA showed strong activation in neutrophil-lineage cells, while elastase-positive granules were stained red-brown (red arrow).

RE-6, and RE-12 groups were low. At $48 \mathrm{~h}$, the values of the RE-0, RE-3, and RE-6 groups were high while the value of the RE-12 group was low (Fig. 5).

\section{Discussion}

It has been reported that sivelestat sodium hydrate (Sivelestat), which is a neutrophil elastase (NE) inhibitor, suppresses the increase of NE activity in animal models of acute lung injury in a dose-dependent manner $(6,7)$. Moreover, Kawabata et al (6) and Hagio et al (7) reported that sivelestat suppresses neutrophil infiltration of the lungs, protein leakage, and bleeding, and also inhibits increases in elastase activity in blood plasma and lung permeability resulting from lung defects. There are also reports that endotoxin, cobra toxin (which is a complement activator), and hydrochloric acid cause lung injury in animal models. However, no reports have examined the suppressant efficacy of NE inhibitors in animal models of radiation-induced lung injury. Following lung irradiation, the levels of cytokines such as TNF- $\alpha$, IL-1,

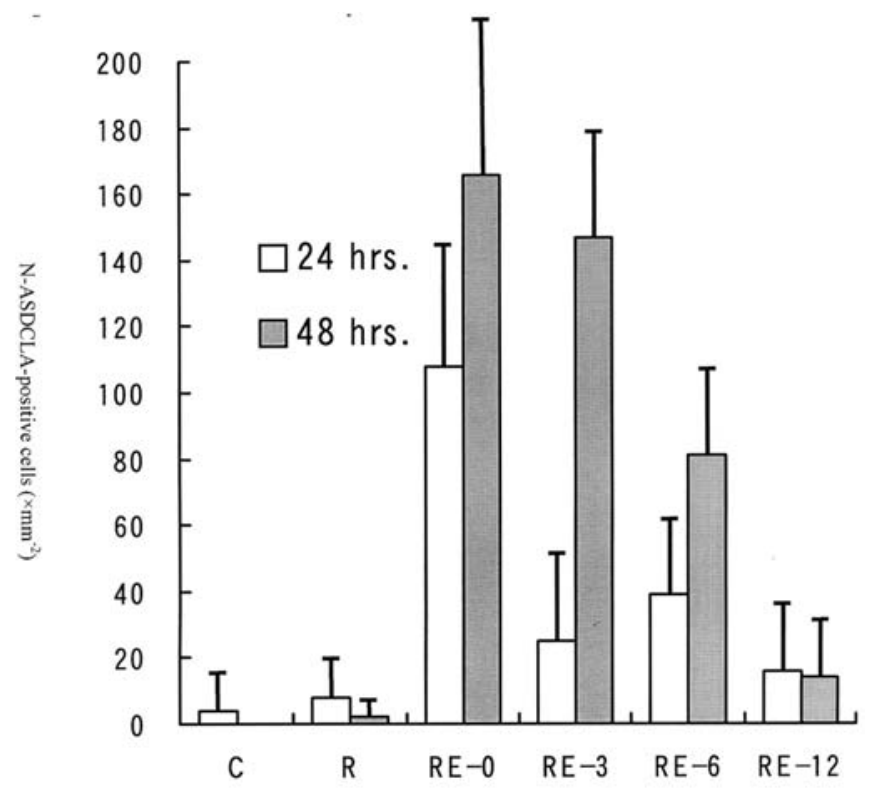

Figure 5. The number of N-ASDCLA-positive cells. The number of NASDCLA-positive cells increased in the sivelestat-administered groups, while group $\mathrm{R}$ had low values. Twenty-four hours after irradiation, the RE-0 group value was high while the values for the RE-3, RE-6, and RE-12 groups were low. At $24 \mathrm{~h}$ after irradiation, compared to the $\mathrm{R}$ group, NASDCLA-positive cells were increased in all the sivelestat-administered groups; RE-0 ( $\mathrm{p}<0.01), \mathrm{RE}-3$ ( $\mathrm{p}=0.14), \mathrm{RE}-6(\mathrm{p}<0.01)$, and RE-12 ( $\mathrm{p}=0.37)$. In the RE-0 and RE- 6 groups, N-ASDCLA-positive cells were significantly increased. At $48 \mathrm{~h}$, the values for the RE-0, RE-3, and RE-6 groups were high while the RE-12 group value was low. Compared to the R group, NASDCLA-positive cells were significantly increased in all the sivelestatadministered groups except group RE-12; RE-0 ( $p<0.01)$, RE-3 ( $<<0.01)$, RE-6 ( $<<0.01)$, and RE-12 ( $\mathrm{p}=0.09)$.

and IL-6 increase causing lung injury by the following processes: i) the activation of neutrophils, ii) the accumulation of activated neutrophils in the lung, iii) the release of elastase, and iv) endothelial and epithelial injury in pulmonary blood vessels (21-27).

The C57BL/6J mouse is known to be sensitive to radiation, and irradiating its lungs with 12 Gy causes radiation pneumonitis $(28,29)$. In our research, irradiation of the murine lung caused lung injury characterized by an increase in pulmonary vascular permeability due to active neutrophil elastase in the blood plasma.

$\mathrm{NE}$ activity in the blood plasma was suppressed $24 \mathrm{~h}$ after irradiation. This signified a noticeable decrease, especially in mice treated $3 \mathrm{~h}$ after irradiation (RE-3) and in mice treated $6 \mathrm{~h}$ after irradiation (RE-6). It was apparent $48 \mathrm{~h}$ after irradiation that the NE activity in the blood plasma of sivelestat-administered mice increased compared to that in the plasma of the non-administered group. This indicates that sivelestat inhibited an increase in NE activity in the blood plasma of the mice which had experienced radiation-induced lung injury. Since we administered only one dose of sivelestat to the mice in our experiment, there was a re-increase in $\mathrm{NE}$ activity in the blood plasma after $48 \mathrm{~h}$, despite the fact that NE activity had been successfully suppressed after the 24-h mark. We reasoned that the low count of N-ASDCLApositive cells in the pulmonary tissue was due to elastase released extracellularly in the radiation-administered group 
(R). Moreover, we discovered strong activation of neutrophils in the group administered sivelestat. Since sivelestat suppressed the release of NE extracellularly, the number of $\mathrm{N}$-ASDCLA-positive cells in the pulmonary tissue increased. The group that was administered sivelestat immediately after irradiation (RE-0) showed a significant increase in positive cell counts $24 \mathrm{~h}$ after irradiation. However, because sivelestat has a half-life of only several hours and because there is a 3-h time lag before the increase of cytokines TNF- $\alpha$, IL- 1 , and IL-6 activates neutrophils, sivelestat appears to have induced a quicker response within the cell than in the peripheral blood (30). This would explain why NE activity remained uninhibited in the RE- 0 group. Therefore, we believe that it is more effective to administer sivelestat in the early stages of lung injury. Also, we believe that the increase in NE activity may likely be suppressed by continuous or multiple administrations of sivelestat. It appears that the decrease in the N-ASDCLA-positive cell count in the RE-3, RE-6, and RE-12 groups, compared to those in the RE-0 group, was due to the extracellular release of elastase, which would account for the increase in NE activity in blood plasma. Furthermore, while NE activity in the blood plasma increased, N-ASDCLApositive cell counts increased after $48 \mathrm{~h}$ because the inhibitory effect of sivelestat decreased. For these reasons we believe that sivelestat inhibits the increase in NE activity in the blood plasma caused by radiation-induced lung injury and also suppresses the development of lung injury. This inhibition of lung injury was obvious from an improvement in histopathologic indicators.

Endogenous protease inhibitors such as $\alpha 1-\mathrm{P} 1$ are unable to suppress enough $\mathrm{NE}$ activity in inflamed areas $(31,32)$. NE can damage tissue, even when there is a considerable amount of protease inhibitor in vivo, for the following reasons. The molecular mass of the endogenous protease inhibitor is too large for it to lodge between the neutrophil and tissue, and reactive oxygen species released by the neutrophil eliminate the endogenous protease inhibitor. Also, this inhibitor may have significantly less effect on substrate tissue-bound NE (33). Unlike the endogenous protease inhibitor, sivelestat (a low molecular mass inhibitor) is able to lodge between the neutrophil and tissue, and the structure of sivelestat may not be susceptible to degradation by reactive oxygen (34). Moreover, it is known that sivelestat does not decrease tissue activity against tissue-bound NE. This may be the reason why sivelestat effectively suppresses the development of acute lung injury despite the fact that there is a considerable amount of protease inhibitor in vivo.

In conclusion, neutrophil elastase plays an important role in the development of radiation-induced lung injury. Sivelestat sodium hydrate is thus expected to suppress radiation-induced lung toxicity by suppressing neutrophil elastase release from neutrophils. Therefore, sivelestat is more effective when administered during the early stages of lung injury.

\section{References}

1. Graeme WM, Pharm B, Samuel NB and Samuel NB: Radiation and the lung: A reevaluation of the mechanisms mediating pulmonary injury. Int J Radiat Oncol Biol Phys 31: 361-369, 1995.
2. Bayle JY, Nesme P, Bejui-Thivolet F, Loire R, Guerin JC and Cordier JF: Migratory organizing pneumonitis primed by radiation therapy. Eur Respir J 8: 322-326, 1995.

3. Hong JH, Chiang CS, Tsan CY, Lin PY, Wu CJ and McBride WH: Can short-term administration of dexamethasone abrogate radiation-induced acute cytokine gene response in lung and modify subsequent molecular responses? Int J Radiat Oncol Biol Phys 51: 296-303, 2001.

4. Ward HE, Kemsley L, Davies L, Holecek M and Berend N: The effect of steroids on radiation-induced lung disease in the rat. Radiat Res 136: 22-28, 1993

5. Sekine I, Sumi M, Ito Y, et al: Retrospective analysis of steroid therapy for radiation-induced lung injury in lung cancer patients. Radiother Oncol 80: 93-97, 2006.

6. Kawabata K, Hagio T, Matsumoto S, Nakao S, Orita Y, Aze Y and Ohno H: Delayed neutrophil elastase inhibition prevents subsequent progression of acute lung injury induced by endotoxin inhalation in hamster. Am J Respir Crit Care Med 161: 2013-2018, 2000.

7. Hagio T, Nakao S, Matsuoka H, Matsumoto S, Kawabata K and Ohno H: Inhibition of neutrophil elastase activity attenuates complement-mediated lung injury in the hamster. Eur J Pharmacol 426: 131-138, 2001

8. Taooka Y, Maeda A, Hiyama K, Ishioka S and Yamakido M: Effect of neutrophil elastase inhibitor on bleomycin-induced pulmonary fibrosis in mice. Am J Respir Crit Care Med 156: 260-265, 1997.

9. Folkesson HG, Matthay MA, Hébert CA and Broaddus VC: Acid aspiration-induced lung injury in rabbits is mediated by interleukin-8-dependent mechanisms. J Clin Invest 96: 107-116, 1995.

10. Hagio T, Matsumoto S, Nakao S, Abiru T, Ohno H and Kawabata K: Elastase inhibition reduced death associated with acid aspiration-induced lung injury in hamsters. Eur J Pharmacol 488: 173-180, 2004.

11. Wiener-Kronish JP, Gropper MA and Matthay MA: The adult respiratory distress syndrome: definition and prognosis, pathogenesis and treatment. Br J Anaesth 65: 107-129, 1990.

12. Tamakura S, Ogawa M, Aikawa N, et al: Relationship between neutrophil elastase and acute lung injury in humans. Pulm Phamacol Ther 17: 271-279, 2004.

13. Ryugo M, Sawa Y, Tkano H, et al: Effect of a polymorphonuclear elastase inhibitor (sivelestat sodium) on acute lung injury after cardiopulmonary bypass: findings of a double blind randomized study. Surg Today 36: 321-326, 2006.

14. Inoue Y, Tanaka H, Ogura H, et al: A neutrophil elastase inhibitor, Sivelestat improves leukocyte deformability in patients with acute lung injury. J Trauma 60: 936-943, 2006.

15. Peterson MW, Walter ME and Nygaard SD: Effect of neutrophil mediators on epithelial permeability. Am J Respir Cell Mol Biol 13: 719-727, 1995.

16. Suttorp N, Nolte A, Wilke A and Drenckhahn D: Human neutrophil elastase increases permeability of cultured pulmonary endothelial cell monolayers. Int J Microcirc Clin Exp 13: 187-203, 1993.

17. Owen CA, Campbell MA, Sannes PL, Boukedes SS and Campbell EJ: Cell surface-bound elastase and cathepsin G on human neutrophils: a novel, non-oxidative mechanism by which neutrophils focus and preserve catalytic activity of serine proteinases. J Cell Biol 131: 775-789, 1995.

18. Rocker GM, Pearson D, Wiseman MS and Shale DJ: Diagnostic criteria for adult respiratory distress syndrome: Time for reappraisal. Lancet 333: 120-123, 1989.

19. Havemman K and Gramse M: Physiology and pathophysiology of neutral proteinases of human granulocytes. Adv Exp Med Biol 84: 1-20, 1984.

20. Kawabata K, Hagio T and Matsuoka S: The role of neutrophil elastase in acute lung injury. Eur J Pharmacol 451: 1-10, 2002.

21. Claudia ER, Daniela U, Falk W, et al: The bronchiolar epithelium as a prominent source of pro-inflammatory cytokines after lung irradiation. Int J Radiat Oncol Biol Phys 61: 1482-1492, 2005.

22. Johnston CJ, Piedboeuf B, Rubin P, Williams JP, Baggs R and Finkelstein JN: Early and persistant alterations in the expression of interleukin-1 $\alpha$, interleukin- $1 \beta$ and tumor necrosis factor $\alpha$ mRNA levels in fibrosis-resistant and sensitive mice after thoracic irradiation, Radiat Res 145: 762-767, 1996.

23. Rubin P, Johnston CJ, Williams JP, McDonald S and Finkelstein JN: A perpetual cascade of cytokines postirradiation leads to pulmonary fibrosis. Int J Radiat Oncol Biol Phys 33: 99-109, 1995. 
24. Bedard M, McClure CD, Schiller NL, Francoeur C, Cantin A and Denis M: Release of interleukin-8, interleukin-6, and colony-stimulating factors by upper airway epithelial cells: implications for cystic fibrosis. Am J Respir Cell Mol Biol 9: 455-462, 1993.

25. Nakamura H, Yoshimura K, McElvaney NG and Crystal RG: Neutrophil elastase in respiratory epithelial lining fluid of individuals with cystic fibrosis induces interleukin- 8 gene expression in a human bronchial epithelial cell line. J Clin Invest 89: 1478-1484, 1992.

26. O'Brien-Ladner A, Nelson ME, Kimler BF and Wesselius LJ: Release of interleukin-1 by human alveolar macrophages after in vitro irradiation. Radiat Res 136: 37-41, 1993.

27. Beetz A, Messer G, Oppel T, Van Beuningen D, Peter RU and King P: Induction of interleukin 6 by ionizing radiation in a human epithelial cell line: Control by corticosteroids. Int J Radiat Biol 72: 33-43, 1997.

28. Kraus R, Steinberg F, Rehn B, Brush J and Streffer C: Radiation-induced changes in lung tissue and development of fibrosis determined by quantitative morphometric methods. J Cancer Res Clin Oncol 117: 27-32, 1991.
29. Franko AJ and Sharplin J: Development of fibrosis after lung irradiation in relation to inflammation and lung function in a mouse strain prone to fibrosis. Radiat Res 140: 347-355, 1994.

30. Woloschak GE, Chang-Liu C, Jones PS and Jones CA: Modulation of gene expression in Syrian hamster embryo cells following ionizing radiation. Cancer Res 50: 339-344, 1990.

31. Weiss SJ: Tissue destruction by neutrophils. N Engl J Med 320: 365-376, 1989.

32. Matheson NR, Wong PS and Travis J: Enzymatic inactivation of human alpha-1-proteinase inhibitor by neutrophil myeloperoxidase. Biochem Biophys Res Commun 88: 402-409, 1979.

33. Weitz JI, Huang AJ, Landman SL, Nicholson SC and Silverstein SC: Elastase-mediated fibrinogenolysis by chemoattractant-stimulated neutrophils occurs in the presence of physiologic concentrations of antiproteinases. J Exp Med 166: $1836-1850,1987$.

34. Kawabata K, Moore AR and Willoughby DA: Impaired activity of protease inhibitors towards neutrophil elastase bound to human articular cartilage. Ann Rheum Dis 55: 248-252, 1996. 